\title{
The Role of New Media in Developing the Sports Practice of the Students in Primary Stage (A Field Study at Mansouri Ben Abdallah School)
}

\author{
Drim Fatima Zahra ${ }^{1}$, Abassi Yacine ${ }^{2 *}$ and Sabira Ferahtia ${ }^{3}$ \\ ${ }^{1}$ Newmedia and society, University of Mostaganem, Algeria \\ ${ }^{2}$ Physical preparation for athletes, University of Algiers 3, Algeria \\ ${ }^{3}$ Institute of Physical Education and Sports, University of Algiers 3, Algeria
}

Submission: May 14, 2018; Published: May 22, 2018

*Corresponding author: Abassi Yacine, Physical preparation for athletes, University of Algiers 3, Algeria, Tel: 0799873807; Email: abassi141@gmail.com

Abstract

New media help to shape the social, cultural and moral structure of society, through creation values, exchange of ideas and help to participate in trends of people in sports topics that have formed a special audience. So, the study is concerned with the role of new media and techniques in stitching the culture of sports practice in children through digital devices, Electronic games and network applications. That the interest of sports field in new media means touching the various segments of society, including the child who has to maintain his healthy body by activating sports practice and sports culture

Keywords: New Media; Digital Games; Sports Culture.

\section{Introduction}

The countries of the world are racing to achieve cultural integration in order to achieve cultural growth, relying on the total number of civil society institutions, including the media institutions that depend on countries to develop their horizons. As sports are part of cultural life, sports activity is a necessity for mental, intellectual, and cultural issues. Therefore, the interest in the term physical culture through the new media and varied in the provision of instructions and skills and rules of physical activity using multimedia from text, voice, image that the media contributes to the process of interpretation and guidance and education, entertainment through programs to the public.

The children's category has been significantly influenced by the content and publications of the media interested in sport and physical activity through the wide spread of the Internet, mobile devices such as smart phones and electronic panels that are accessible to most children inside or outside their ester. In this study, we will attempt to determine the extent to which the new media in their network and digital applications can be a positive focus in the dissemination of instruction and mathematical and physical skills and to strengthen the youth's mathematical viability through a study of a sample of children exposed to sports practices through new media applications .

\section{Problematic Study}

Media, audio, visual and readable media are an important source of guidance and education in any society. This is an important factor in building and shaping societies. Media organizations are a trust and responsibility that is far superior to educational institutions and civil society institutions in terms of interest in society and its requirements. The new media from social networking sites and electronic publishing sites is one of the means of transferring news and exchanging information, thus forming the cognitive and cognitive structure of the individual, allowing him to express his opinion and awareness about different issues and the ability to analyze them and take positions and change behaviors and patterns. Especially that contemporary society can't continue without these means. It is clear that the new media applications and techniques have become a central part of social construction and have become a stand-alone industry, and with the development of the media and its diversity in its diverse characteristics and the concerns of the public.

The child as a social unit interested in the media of all kinds to pay attention to his concerns and needs and maintain his 
mental and physical development right through the variety of programs and sports packages known as sports as the launch of the Olympic Games, the presentation of various football patrols and other sports competitions, especially that the child today is the child technology that grew up with her And live in his diary, because of his age and interest is closely related to the games of movement and forces and the handling of some sports activities on the virtual reality through electronic devices, this study to address the contribution of means To inform the new in the development of sports sense of the Algerian child or is a danger to his health and raise it.

\section{Study 's Concepts}

\section{New Media}

Means the total of devices, technologies and advanced means that emerged with the emergence of the Internet and the new media, which grew rapidly in the twenty-first century after the revolution of computing and communications, based on information media texts, tables, graphs, still images, colour and movement audio and video, integrated and integrated with Cognitive abilities to deliver messages to their target audiences [1].

\section{Digital Games}

It is an intellectual activity and an Internet based information system, consisting of video games, computer games, mobile games, software and information processing, input and output. These games may be played collectively or individually.

\section{Sport Culture}

Is a specific pattern of the group of knowledge, information, experiences and gains possessed by the individual in the field of sports, so that the child's physical culture goes beyond the physical concept to attention to what is mental to include the psychological, moral, aesthetic, recreational and cultural concepts acquired by the child during the stage of his education and help him to respect the general mathematical system and knowledge of the rules Organization of Sport [2].

\section{The Importance and Objectives of the Study}

The importance of the study is determined by the importance of its three components, media, children and sports, as it helps to reveal the positive media in its mathematical content aimed at the sensitive audience (children) and the value of the media. Which is protected by these contents in the construction of a generation with a sound sports culture that prevents him from aggressive behaviour and violent in his physical practices and directed to the successful practices and useful to his mind and body.

\section{The objectives of the Study are as Follows:}

a) The ability to correct the new media and its modern techniques to disseminate content publications and games that are suitable for the good taste of the child's sport. b) The establishment of a sports system based on the rules, laws and activities governing the safety of the child from electronic risks.

c) Activate media Framework for their contribution to raising awareness of the importance of physical activity on the various aspects of the child both personal and human.

\section{Study Procedure}

The study focuses on the research community of children as the stage of childhood begins from the end of breastfeeding to adolescence [3]. Since the study is specific to the use of new media by this group the focus was more on the category exposed to mathematical content through means New Media. The field study helps us with quantitative statistics and based on the qualitative analysis to reveal the current facts regarding the nature of this new phenomenon and its backgrounds and results after dealing with the sample members and the subject closely [4]. The research community includes primary school pupils in the state of Bechar between the ages of 9 and 11 years, from 2015 to 2016, the period in which there has been a development in the spread of the phenomenon and its participation in its characteristics [5].

We have adopted the random sampling method that must carry all the characteristics of the original society. The questionnaire was distributed to children who use the new media and those interested in electronic games on the digital applications, which are 160 students of the sample, which is sufficient in our study. The questionnaire was chosen as a research tool to identify the attitudes of students and their habits of using the new media and their interaction with the mathematical content on the applications of digital devices and over the Internet, in order to reveal the role of the contents of these means in the development of sports sense in the child. The questionnaire was divided according to the study's axes to:

a) Sports in the new media

b) Effect of electronic games on the child

c) Sports culture

\section{Analyze Study 's Result}

\section{Sport in the Media}

Don't neglect the media packages of all types of sports content targeted to all groups of society. It was the interest of children as the first young people to build society in order to develop their ideas and establish sports practice [6], as is the case with the emergence of new media based on the Internet, We find the turn of children towards this new born because of the privileges and characteristics that distinguish it from its traditional. In the study of the usage habits of selected sample children, the results of the daily use of new media and social web applications in various forms, Facebook, Twitter, YouTube, [7] 
$26.25 \%$, and $61.25 \%$ We note the reluctance of $12.02 \%$ of them to trade these media within their families or communities, due to interest in their lessons and go out to play with their friends (Figure 1).
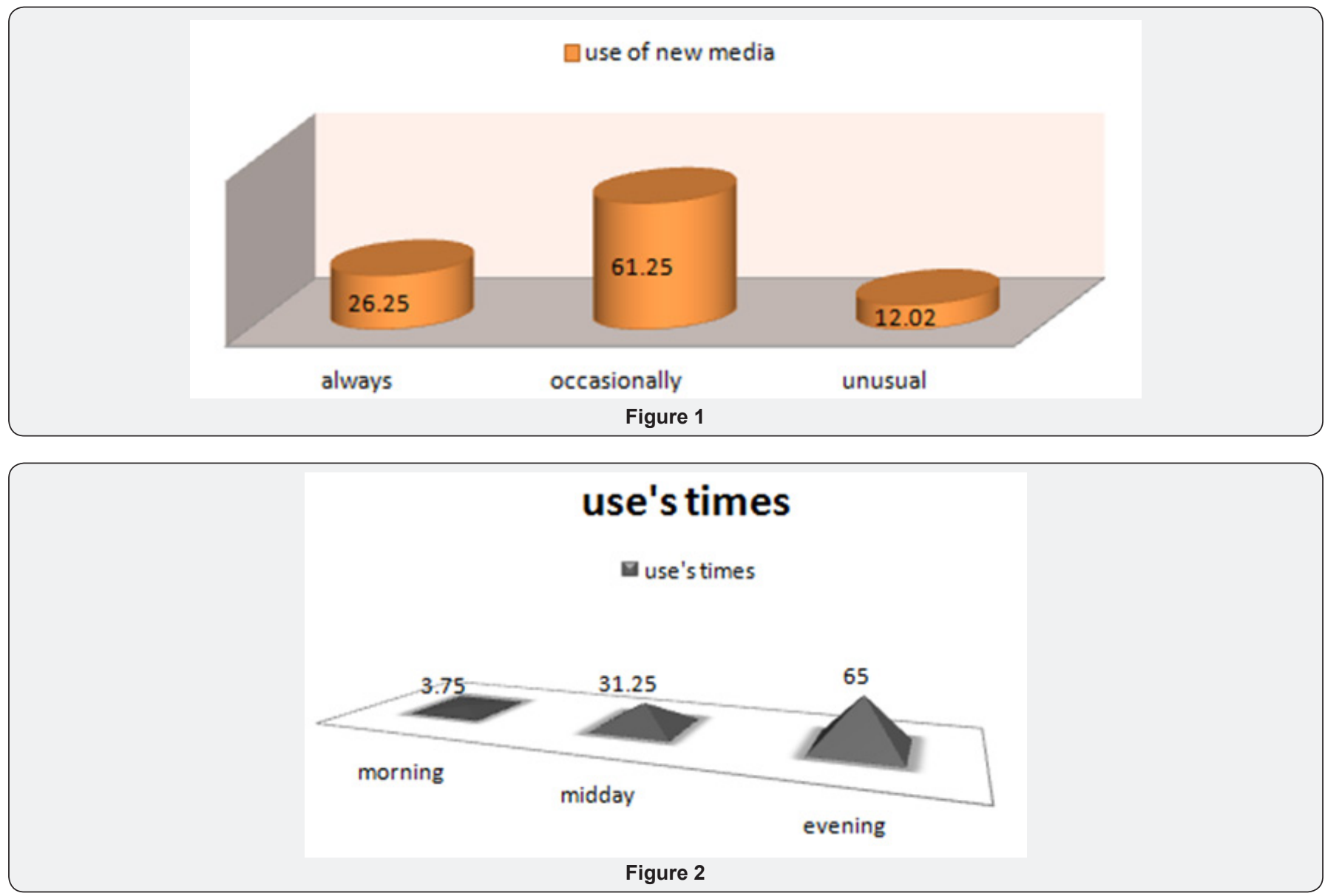

\section{electronic media using by child}

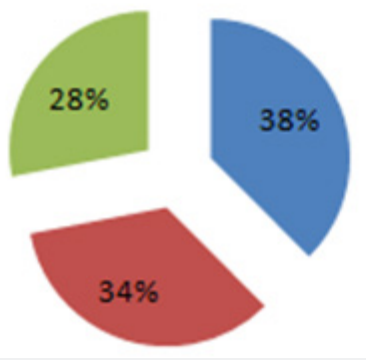

acomputer

E-tablets

- smat phones

Figure 3

School holidays and vacations represent an area of 3.75\% in the morning, $31.25 \%$ midday, and $65 \%$ in the evening, after full-time study and completion of their how works (Figure 2). In addition, $38 \%$ of children care about exercising on the computer, $34.5 \%$ of the students uses the easy-to-use electronic tablets, while the sample items use about $28 \%$ of the use of smart phones. A significant proportion of this generation, which is experiencing rapid transformations and information flows in the field of technology and high-speed Internet (Figure 3) [8].

\section{Effect of Electronic Games on the Child}

The term "play" is directly linked to childhood, and even the new media has carried the wave of electronic games as a new form that links the child's relationship to digital media [9]. Of the basics of spontaneous play on the ground, they accounted for about $64.3 \%$, while $35.6 \%$ of them recognize the importance of the applications of games and sports on electronic devices such as smart phones and paintings of the content is sufficient and 
varied and simplified in an easy and enjoyable, such as action games and movement, Football and participation and interaction with others sometimes in virtual reality, and also the ability to see the news of sports celebrities, and learn more about the rules of sports activities (Figure 4). Some of the principles taken by some of the study respondents are the continuous follow-up of sports content in the new media: a) Safety of mind in body safety $20 \%$

b) Imitation of movements and child interaction with sports content $50.6 \%$

c) Gain Spiritual Culture 8.7\%

d) Identify the types of sport and learn techniques and rules of physical activity $20.6 \%$.
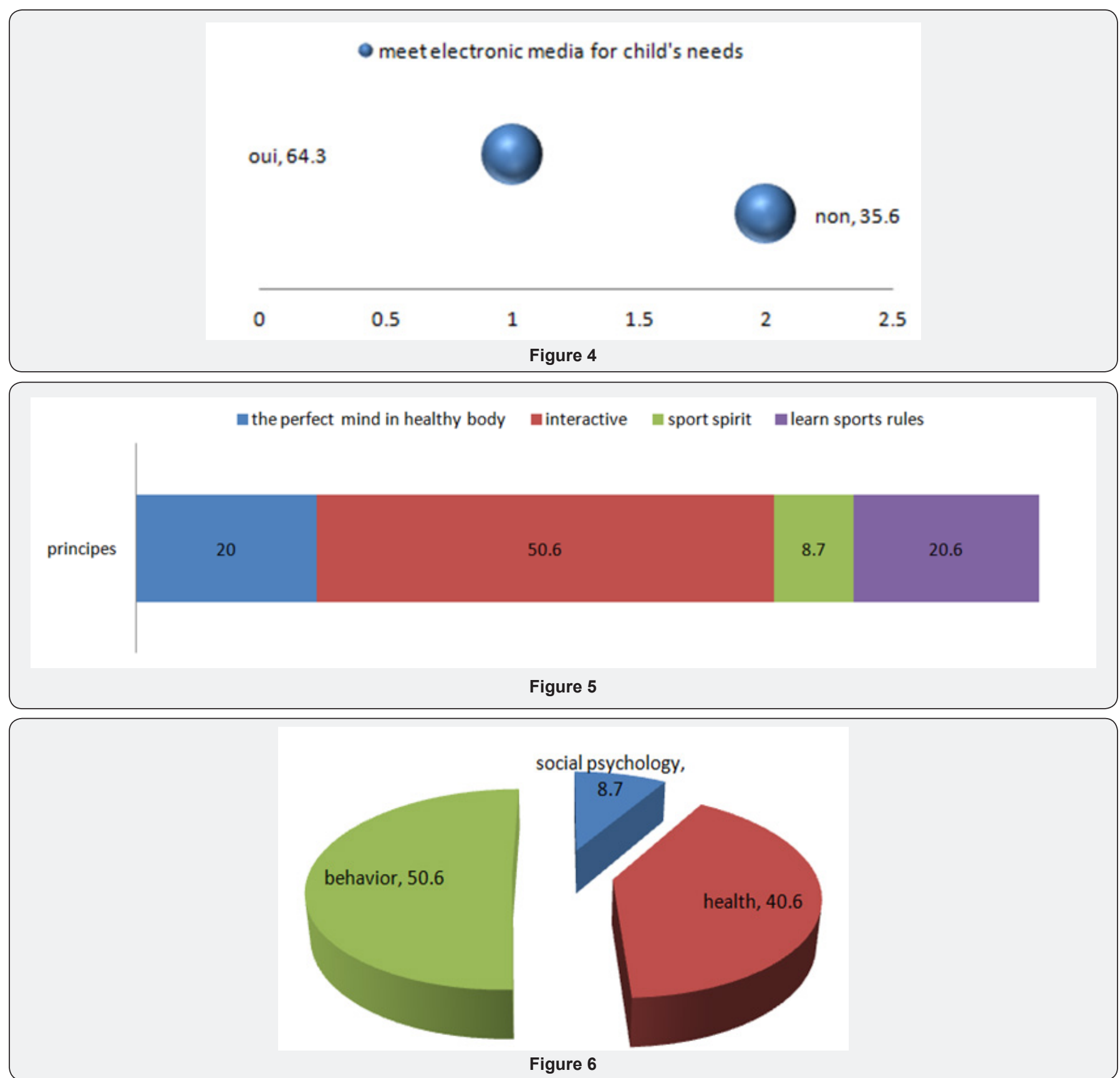

While the new media space affects the children's behaviour negatively, by isolating and refusing to go out to play in fact $8.7 \%$, causing health risks to the eye, laziness, inactivity and psychological damage such as depression and child addiction to electronic devices $40.6 \%$. Continuous exposure to the contents of sport and movement can be reflected in the behaviour of the child with aggression and violence, which is the largest problem

of the respondents by about $50.6 \%$ (Figures 5 \& 6).

\section{Sports Culture}

Sports media, which relies on advanced techniques in presenting information and physical activity in modern formations, has been an important and influential factor in the educational process [10], because it directly addresses young 
people and includes all kinds of sport. It has changed in the way we think and how we evaluate the media messages that form the culture of the individual. From statistical reading to quantitative data, it is clear that more than half of the respondents (46.8\%) are interested in watching and receiving sports content based on the new media, web applications and electronic devices with the Internet, and it is fertile ground for acquiring information in a fun and attractive way to integrate media from texts, pictures, Colours, motion, and video clips ... in addition to the interactive and participation in the practice of sports within the electronic space by $26.5 \%$.

In contrast, the remaining $26.8 \%$ of respondents support the acquisition of sports culture from traditional media such as newspapers, radio and television as mass media that maintain the intimacy between members of society and the ease of availability within the home and not cost. It is worth mentioning that sports programs in the media, both traditional and new, play a major role in the dissemination of sports culture, literacy and the establishment of educational and social values within the society in general and children in particular dealing with them.

\section{Conclusion and Recommandations of the Study}

Sport culture is one of the components of the general culture of the individual in general and the child in particular, which is working on its development. It is represented by sound mental activity and positive physical application. It also helps to shape and crystallize the personality of the child and provide him with knowledge, ways of thinking and new behavioural patterns. Among the groups, and this is only according to a programmed curriculum that the media channels, techniques and modern means to promote it by increasing awareness of the importance of physical activity sports child. In this context, the study attempted to propose a number of recommendations in light of the conclusions and statistics of the questionnaire for this segment of society, as follows:

a) Maintain and maintain the relationship between the child and the media through continuous monitoring and regulation of usage habits. b) To develop sports information policies based on scientific methodology that takes in to account the scientific and cognitive level of the Algerian child.

c) Adjust the use of electronic devices with stages of child growth, to avoid damage and psychological, social, health, behavioral risks.

d) Parents, educators and teachers are interested in the physical activity of the child on the ground and the diversification of sports practices for fear of the child's access to and addiction to the virtual world.

e) To promote awareness programs and the culture of sport practice through seminars, open doors and seminars, and to combine sports and psychological experts to protect and preserve children.

\section{References}

1. Sadek A (2008) New media concept, tools and applications. Dar Elshorok, Jordan.

2. Alkhawlli A, Adnan M (1996) Sport culture. El Fiker El Arabi, Egypt.

3. El Fikki H (1995) Study on psychology of growth. Dar El kalam, Kuwait.

4. Zerwati R (2002) Training of methodology of scientific research on sociologies sciences. Dar El Homa, Algeria.

5. Bouhouresh A, Adnibbat M (2001) The method of preparing a scientific research. Algeria.

6. Sekaker F (1999) Play Folder17 Electronic Arabic Encyclopedic Syria.

7. Briggs Mark (2007) Journalism 2.0: How to survive and thrive a digital literacy for the information age, knight foundation, Austin, United States.

8. Boukhnoufa A (2007) Children and information revelation, Arab Radio Federation magazine, Tunisia, Africa.

9. Al shahror H (2008) Electronic games on globalism age. Dar Elmassira, Jordan.

10. Karem Eddine L (2007) Children's program and needs, Arab Radio Federation magazine, Tunisia, Africa.

\section{Your next submission with Juniper Publishers} will reach you the below assets

- Quality Editorial service

- Swift Peer Review

- Reprints availability

- E-prints Service

- Manuscript Podcast for convenient understanding

- Global attainment for your research

- Manuscript accessibility in different formats

( Pdf, E-pub, Full Text, Audio)

- Unceasing customer service

Track the below URL for one-step submission https://juniperpublishers.com/online-submission.php 